\title{
Agrin Controls Synaptic Differentiation in Hippocampal Neurons
}

\author{
Christian M. Böse, ${ }^{1}$ Dike Qiu, ${ }^{1}$ Andrea Bergamaschi, ${ }^{3}$ Biagio Gravante, ${ }^{3}$ Mario Bossi, ${ }^{2}$ Antonello Villa, ${ }^{2}$ \\ Fabio Rupp, ${ }^{1}$ and Antonio Malgaroli ${ }^{3}$ \\ ${ }^{1}$ Department of Neuroscience, The Johns Hopkins University, School of Medicine, Baltimore, Maryland 21205, \\ ${ }^{2}$ Microscopy and Image Analysis, University of Milan School of Medicine, and ${ }^{3}$ Department of Biological and Technological \\ Research, Scientific Institute San Raffaele, 20123 Milano, Italy
}

\begin{abstract}
Agrin controls the formation of the neuromuscular junction. Whether it regulates the differentiation of other types of synapses remains unclear. Therefore, we have studied the role of agrin in cultured hippocampal neurons. Synaptogenesis was severely compromised when agrin expression or function was suppressed by antisense oligonucleotides and specific antibodies. The effects of antisense oligonucleotides were found to be highly specific because they were reversed by adding recombinant
\end{abstract}

agrin and could not be detected in cultures from agrin-deficient animals. Interestingly, the few synapses formed in reduced agrin conditions displayed diminished vesicular turnover, despite a normal appearance at the EM level. Thus, our results demonstrate the necessity of agrin for synaptogenesis in hippocampal neurons.

Key words: agrin; synaptogenesis; synapses; primary hippocampal neurons; agrin antibodies; antisense oligonucleotides
The fidelity of neural transmission depends on interactions of a large number of presynaptic and postsynaptic molecules. Despite the importance of these processes for neural communication, the mechanisms controlling the assembly and the targeting of molecules to synapses remain primarily unknown (Sanes et al., 1998). One hypothesis of synapse formation proposes that growth cones secrete factors that bind to specific receptors located on the plasma membrane of the target cell (McMahan, 1990). Signaling cascades activated via these receptors lead to the recruitment and/or the targeted insertion of postsynaptic molecules at contact sites. The discovery of the synaptic differentiation factor agrin supports this model (Nitkin et al., 1987). Agrin is an extracellular matrix proteoglycan necessary for the aggregation of the ACh receptor (AChR) at developing neuromuscular junctions (NMJs), which is transcribed from a single gene but exists in different isoforms that are produced by alternative splicing (Rupp et al., 1991, 1992; Ruegg et al., 1992; Smith et al., 1992; Tsim et al., 1992). Alternative splicing at a specific site, referred to as the z-site in rodents, affects the AChR-clustering activity of agrin (Ferns et al., 1992, 1993; Ruegg et al., 1992). Recently, mice that either express extremely low levels of agrin transcripts or do not express highly active $(\mathrm{z}+)$ isoforms have been produced. The phenotype of these mutations is very similar; homozygous mutant embryos die late during gestation, and a dramatic reduction in number, size, and density of AChR clusters is observed at NMJs (Gautam et al., 1996; Burgess et al., 1999). These results, together with experiments using antiagrin antibodies to block agrin function in vitro (Cohen and Godfrey, 1992; Reist et al., 1992; Campagna et al., 1997), demonstrate that agrin is necessary for the differentiation of NMJs.

Despite the evidence supporting the role of agrin in the formation of NMJ, it is still unknown whether synaptogenesis in the CNS is regulated similarly. A series of observations suggests that agrin may have a more widespread role and may also control the formation of synapses in the CNS. Agrin mRNA and immunoreactivity

\footnotetext{
Received May 22, 2000; revised Sept. 18, 2000; accepted Sept. 21, 2000.

This work was supported by grants from the National Institutes of Health (R29MB 51158), the Esther A. and Joseph Klingenstein Fund, and the Muscular Dystrophy Association to F.R. and by grants from the telethon, Human Frontiers, and Ministero dell'Università e della Ricerca Scientifica e Tecnologica to A.M. C.M.B. was supported by a fellowship of the Swiss Federal Institute of Technology. We thank D. Ginty, A. Kolodkin, R. Huganir, C. Hopf, and D. Linden for helpful discussions. We also thank M. Diana for some preliminary electrophysiological recordings.

Correspondence should be addressed to Dr. Fabio Rupp, HySeq, Inc., 670 Almanor Avenue, Sunnyvale, CA 94085. E-mail: frupp@sbh.com.

Copyright (C) 2000 Society for Neuroscience 0270-6474/00/209086-10\$15.00/0
}

can be detected in CNS neurons, where the temporal pattern of expression of agrin parallels synaptogenesis (Hoch et al., 1993; O'Connor et al., 1994; Stone and Nikolics, 1995; N. A. Cohen et al., 1997). Agrin is targeted to axons in spinal cord neurons, and it is secreted from hippocampal neurons (Dutton et al., 1995; Escher et al., 1996). Electrical activity regulates agrin expression in hippocampal neurons (O'Connor et al., 1995; N. A. Cohen et al., 1997). Agrin $z(+)$, but not $z(-)$, isoforms are able to induce the phosphorylation of the transcription factor cAMP response element-binding protein (CREB) in primary hippocampal neurons (Ji et al., 1998). In addition, a recent study suggests that diminished agrin expression leads to morphological and synaptic alterations in primary hippocampal neurons (Ferreira, 1999). However, synaptogenesis occurs normally in primary hippocampal and cortical neurons derived from agrin-deficient mice (Li et al., 1999; Serpinskaya et al., 1999). A caveat in assessing results obtained from nullmutant mice produced by homologous recombination is the possibility of functional redundancy and/or activation of compensatory mechanisms during development. To avoid these complications, we tested the possibility that agrin functions as a synaptic differentiation factor in primary hippocampal neurons. This type of neuronal culture is particularly suited for studies of synaptogenesis because the molecular events associated with the culture and the kinetics of synaptic differentiation have been well characterized and because these neurons form functional synapses (Fletcher et al., 1991; Malgaroli et al., 1995; Rao et al., 1998). Our results show that synaptic differentiation was inhibited when agrin expression or function was suppressed by either agrin-antisense oligonucleotides or anti-agrin antibodies, thus demonstrating the requirement of agrin for synaptogenesis in hippocampal neurons.

\section{MATERIALS AND METHODS}

Antibodies. Monoclonal antibodies specific for synaptophysin, microtubuleassociated protein 2 (MAP-2), actin, and $\mathrm{GABA}_{\mathrm{A}}$ were purchased from Boehringer Mannheim (Indianapolis, IN); those for agrin (m247 and m33) were from StressGen Biotechnologies (Victoria, British Columbia, Canada). Antibodies specific for neuron-specific enolase, synapsin-I, glutamic acid decarboxylase, postsynaptic density 95 (PSD-95), and CREB were purchased from Polysciences (Warrington, PA), Molecular Probes (Eugene, OR), Chemicon (Temecula, CA), Affinity Bioreagents (Golden, $\mathrm{CO}$ ), and New England Biolabs (Beverly, MA), respectively. Antibodies against NR1 were a kind gift from Dr. R. Huganir (Johns Hopkins University, Baltimore, MD). A polyclonal serum specific for GluR1 was raised as described (Molnar et al., 1994). Secondary antibodies conjugated with indocarbocyanine, FITC, and Texas Red were purchased from Jackson ImmunoResearch (West Grove, PA).

Oligonucleotides. Oligonucleotides were synthesized by Oligos Etc. (Wil- 
sonville, OR). All oligonucleotides used in this study were chimeric phosphorothioates (first and last three residues). The antisense oligonucleotides AS and AS2 are overlapping sequences targeted to regions of the rat agrin cDNA spanning the presumptive start codon, and the antisense oligonucleotide ASY is targeted to the Y insertion site (Rupp et al., 1991). The sense oligonucleotide S was synthesized as the reverse complement of the antisense oligonucleotide AS. The scrambled oligonucleotide SC has the same base composition as the antisense oligonucleotide AS but in a random order. Nucleotide sequences are as follows: AS, 5'-GGAGGCATGATACATACAGCTCGAGC-3'; AS2, 5'-TTCCAGTGGCAGAGGAGGCATGATAC-3'; ASY, 5'-GGAACCTTGCGGGATTTCGGAGATTC3';SC, 5'-TGCGGTACGGAAGACACTCCATAAGG-3'; and S, 5'-GCTCGAGCTGTATGTATCATGCCTCC-3'. None of the sequences shows significant homology to known genes in the GenBank database. The oligonucleotides were added at the onset of the cultures and subsequently every $3 \mathrm{~d}$ at the concentrations indicated. The quality of the oligonucleotides is crucial because batches from other suppliers were cytotoxic at much lower concentrations.

Synaptosome preparations. Synaptosomes were prepared as described (Whittaker, 1984) from hippocampi of 21-d-old rats.

Hippocampal cell cultures. Primary hippocampal cell cultures from 3- to 5-d-old [postnatal day 3 (P3)-P5] Sprague Dawley rats were prepared as described previously (Malgaroli et al., 1995; Ji et al., 1998). Briefly, hippocampi were rapidly dissected, dissociated by trypsinization and gentle trituration, and plated onto precoated (poly-D-lysine or poly-D-ornithine; $10 \mu \mathrm{g} / \mathrm{ml}$ ) glass coverslips or Permanox chamber slides (Nalge Nunc, Naperville, IL). Cell cultures from embryonic day 17 (E17) agrin-deficient mice were prepared as described above with the exception that hippocampal cells from each embryo were processed and cultured individually.

Purified recombinant agrin isoforms (50 pM) (Campanelli et al., 1996) were added as described for the oligonucleotides. Agrin (m247) and control antibodies (mouse $\alpha$ rat IgG; Jackson ImmunoResearch) were applied at $150 \mu \mathrm{g} / \mathrm{ml}$ once at the onset of the cultures.

Reverse transcription-PCR analysis. Total RNA was prepared from hippocampal cell cultures by the use of TRIZOL (Life Technologies, Gaithersburg, MD) according to the manufacturer's protocol. cDNA synthesis was performed in $15 \mu \mathrm{l}$ of $1 \times$ Superscript II reverse transcription (RT) buffer, $200 \mu \mathrm{M}$ deoxynucleotide triphosphates (dNTPs), $5 \mu \mathrm{Ci}$ of $\left[\alpha^{-}{ }^{32} \mathrm{P}\right] \mathrm{dCTP}$ (NEN, Boston, MA), $10 \mathrm{~mm}$ DTT with $200 \mathrm{U}$ of Superscript II (Life Technologies), and $0.5 \mu \mathrm{g} / \mathrm{ml}$ oligo-dT (Pharmacia Biotech, Piscataway, NJ) for $90 \mathrm{~min}$ at $37^{\circ} \mathrm{C}$ and terminated by heating at $65^{\circ} \mathrm{C}$ for 20 min. PCR amplifications with agrin-specific primers $(0.2 \mu \mathrm{M})$ and $1 \mu \mathrm{l}$ of cDNA were performed in $50 \mu$ l containing $1 \times$ PCR reaction buffer, $1.5 \mathrm{~mm}$ $\mathrm{MgCl}_{2}, 0.5 \mathrm{~mm} \mathrm{dNTPs}$, and $1 \mathrm{U}$ of Taq polymerase (Display Systems Biotechnology, Vista, CA). Cycle parameters were $1 \mathrm{~min}$ at $95^{\circ} \mathrm{C}, 1 \mathrm{~min}$ at $60^{\circ} \mathrm{C}$, and $2 \mathrm{~min}$ at $72^{\circ} \mathrm{C}$ for 25 cycles. At these parameters the amplification reactions were in the exponential phase. Ten microliters of the reaction products were separated on $8 \%$ polyacrylamide gels. Signals for the individual isoforms were visualized and quantified by the use of a PhosphorImager and ImageQuant 3.3 software (Molecular Dynamics, Sunnyvale, CA). Control PCR amplifications were performed in a similar manner using glyceraldehyde-3-phosphate dehydrogenase (GAPDH)-specific primers. Primer sequences are as follows: rat agrin forward and reverse primers, 5'-CACTGGCCTTTGATGGGCGG-3' and 5'-GTCATAGCTCAGTTGCAGGT-3', respectively; and rat GAPDH forward and reverse primers, 5'-ACCACAGTCCATGCCATCAC-3' and 5'-TCCACCACCCTGTTGCTGTA-3', respectively. Data were analyzed by the use of the Student's $t$ test, and the criterion for statistical significance was $p<0.01$.

Western blot analysis. Cells from hippocampal cultures were scraped into cold lysis buffer containing 1\% Triton X-100, 10\% glycerol, $20 \mathrm{~mm}$ Tris$\mathrm{HCl}, \mathrm{pH}$ 8.0, $150 \mathrm{~mm} \mathrm{NaCl}, 0.5 \mathrm{~mm}$ EDTA, $0.5 \mathrm{~mm}$ EGTA, 1 mM sodium vanadate, and protease inhibitors. After incubation on ice for $30 \mathrm{~min}$, the insoluble material was removed by centrifugation at $16,000 \times g$ for $3 \mathrm{~min}$ at $4^{\circ} \mathrm{C}$. The protein content of the samples was assessed via the $\mathrm{ABC}$ method with a kit from Pierce (Rockford, IL). Equal amounts of protein were separated on 3-8\% Tris-acetate SDS-PAGE gels (Novex, San Diego, CA) and transferred onto polyvinylidene difluoride membranes. After incubation in blocking buffer (PBS containing 3\% casein) for $1 \mathrm{hr}$ at room temperature, blots were probed with the monoclonal antibody m 33 overnight at $4^{\circ} \mathrm{C}$. Membranes were exposed to a horseradish peroxidaseconjugated anti-mouse IgG secondary antibody (Amersham, Arlington Heights, IL), and the signal was visualized via enhanced chemiluminescence (ECL Plus; Amersham) onto x-ray film. The blots were stripped and reprobed with different antibodies.

Immunocytochemistry. Hippocampal cell cultures on glass coverslips or Permanox chamber slides were fixed with $4 \%$ paraformaldehyde and $4 \%$ sucrose in PBS and permeabilized with blocking solution $(0.4 \%$ BSA and $0.4 \%$ saponin in PBS). Incubation with primary antibodies was performed in blocking solution overnight at $4^{\circ} \mathrm{C}$. After washing, cells were incubated at room temperature with species-specific fluorochrome-conjugated secondary antibodies. Fluorescence-containing images were captured with a CCD camera (Dage-MTI, Michigan City, IN) mounted on a Nikon TE 3000 using IP Lab 1.3 software (Scanalytics, Fairfax, VA). Quantification of the number of synapses and/or immunoreactive clusters per neurite area was performed by counting fluorescent puncta on neurites longer than 100 $\mu \mathrm{m}$. Only puncta of threefold or greater intensity above the background fluorescence of the process were considered. No distinction between dendrites and axons was made, and values were normalized for length and thickness of the processes.

Electron microscopy. Standard electron microscopy was performed as described previously (Forti et al., 1997). Briefly, cell monolayers were washed with control Tyrode solution, fixed with $2 \%$ glutaraldehyde and $4 \%$ paraformaldehyde in $0.1 \mathrm{M}$ cacodylate buffer $\left(45 \mathrm{~min} ; 24^{\circ} \mathrm{C}\right)$, and post-fixed with $2 \% \mathrm{OsO}_{4}$. After dehydration in ethanol and overnight infiltration (75\% Epon 812 and $25 \%$ ethanol), samples were embedded in Epon. Ultrathin serial sections $(\sim 60 \mathrm{~nm})$ were doubly stained with uranyl acetate and lead citrate and examined with a Hitachi H-7000 microscope.

Electrophysiological recordings. Hippocampal neurons were continuously perfused with a Tyrode solution containing $119 \mathrm{~mm} \mathrm{NaCl}, 5 \mathrm{~mm} \mathrm{KCl}, 2$ $\mathrm{mm} \mathrm{CaCl}, 2 \mathrm{~mm} \mathrm{MgCl}, 25 \mathrm{~mm}$ HEPES, $30 \mathrm{~mm}$ glucose, $100 \mu \mathrm{M}$ picrotoxin (Sigma, St. Louis, MO), and 25-100 $\mu \mathrm{M}$ APV (Tocris Cookson, St. Louis, MO), adjusted to $305 \mathrm{mOsm}$ and $\mathrm{pH}$ 7.4. Patch electrodes (2-5 M $\Omega$ ) contained $110 \mathrm{~mm}$ Cs-gluconate, $5 \mathrm{~mm} \mathrm{MgCl}, 10 \mathrm{~mm} \mathrm{NaCl}, 0.6-10 \mathrm{~mm}$ EGTA or BAPTA, 2 mM ATP, $0.2 \mathrm{~mm} \mathrm{GTP}$, and $49 \mathrm{~mm}$ HEPES, adjusted to $\mathrm{pH} 7.2$ and $290 \mathrm{mOsm}$. Minis were recorded in $0.5 \mu \mathrm{M}$ tetrodotoxin (TTX; Latoxan, Rosans, France). Other reagents were obtained from Sigma except as noted. Synaptic currents were recorded using an Axopatch 1D amplifier (Axon Instruments, Foster City, CA). Recordings were obtained at the soma of neurons using the standard whole-cell configuration. Each cell was held at a membrane potential $\left(\mathrm{V}_{\text {hold }}\right)$ of -50 or $-70 \mathrm{mV}$, and the series resistance (5-20 M 2 ) was monitored by applying $1-5 \mathrm{mV}$ depolarizing pulses. Presynaptic neurons were stimulated in the vicinity of the cell soma using brief $(100 \mu \mathrm{sec})$ constant-current injections delivered through small glass electrodes filled with physiological saline. Current traces were filtered at $2-5 \mathrm{kHz}$ and stored using a digital tape recorder. Data were digitized off-line from the tape at $10-70 \mathrm{kHz}$ after low-pass filtering at $3-5 \mathrm{kHz}$. The detection of miniature events was semiautomatically performed, as described previously (Forti et al., 1997). Briefly, miniature excitatory synaptic currents (minis) were detected using two threshold-crossing criteria on the current signal and on its first derivative (thresholds, three times background SD). Computer simulations estimated the undetected events to be $<3 \%$ for signal-to-noise ratios $(\mathrm{S} / \mathrm{N})>4$ and $<20 \%$ for $\mathrm{S} / \mathrm{N}$ between 3 and 4 .

Antibody uptake experiments. Hippocampal cultures were grown on glass coverslips for $\geq 15 \mathrm{~d}$. Cultures were incubated for $1 \mathrm{hr}$ at $37^{\circ} \mathrm{C}$ in serumfree medium containing antibodies (affinity-purified rabbit polyclonal serum) specific for the intravesicular N-terminal portion of synaptotagmin-I (Malgaroli et al., 1995) and $1 \mu \mathrm{M}$ TTX. Cells were washed with Tyrode solution $\left(37^{\circ} \mathrm{C}\right)$ and with $\mathrm{PBS}$ at $4^{\circ} \mathrm{C}$, fixed in $4 \%$ paraformaldehyde, and permeabilized for 1-2 $\mathrm{hr}$ at room temperature with $1 \%$ BSA and $0.4 \%$ saponin in PBS. Synapses and dendrites were then retrospectively stained using antibodies specific for synaptotagmin-I (goat) and MAP-2 (mouse). Species-specific, fluorochrome (DTAF-, Cy5-, or Texas Red)-conjugated secondary antibodies were used at 1:100 dilutions (Chemicon and Jackson ImmunoResearch). Coverslips were washed with PBS and mounted on glass slides in Slowfade (Molecular Probes). Microscopy and confocal imaging were performed using an upright Zeiss Axiophot microscope (60× oil-immersion objective) equipped with a 1024 Bio-Rad confocal system with an argon-krypton laser (Bio-Rad). For data analysis, synapses (synaptotagmin-I, goat antibody, and immunoreactive puncta) were identified on the basis of intensity and shape parameters by the use of a computer program written in-house. Fluorescence intensity from the internalized antibody (rabbit) was then measured on a different excitation/ emission channel. Values of intensity were determined near the middle of individual boutons and used for analysis if they exceeded three times the $\mathrm{SD}$ of background fluorescence.

\section{RESULTS}

\section{Antisense oligonucleotide treatment reduces agrin expression specifically}

Three agrin-specific antisense oligonucleotides (referred to as AS, AS2, and ASY; see Materials and Methods for details) were used to assess agrin's function in the development of primary postnatal rat hippocampal neurons. The hypothesis that agrin participates in synapse formation in these neurons was reinforced by results indicating that agrin immunoreactivity was highly enriched in synaptosome preparations from rat hippocampus (Fig. $1 E$ ). Oligonucleotides were applied at the onset of the cultures, which were maintained for 10-15 d. To control for specificity, measurements of agrin mRNA and protein levels in relation to several housekeeping and neuronal proteins were performed in cells treated with antisense, sense, and scrambled oligonucleotides. The effect of the antisense oligonucleotide treatment on the expression of agrin mRNA was evaluated by relative reverse transcription-PCR (RTPCR). Figure 1, $A$ and $B$, shows a comparison between the levels of agrin mRNA expression in control and in sense (S)- and antisense (AS)-treated primary hippocampal neurons over a period of $10 \mathrm{~d}$. Agrin mRNA expression was normalized to the expression of the 
A

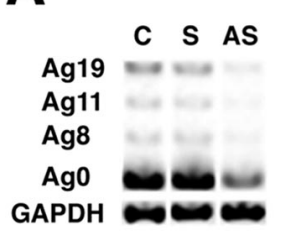

B

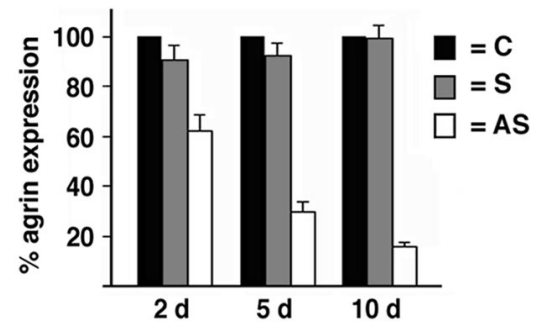

C
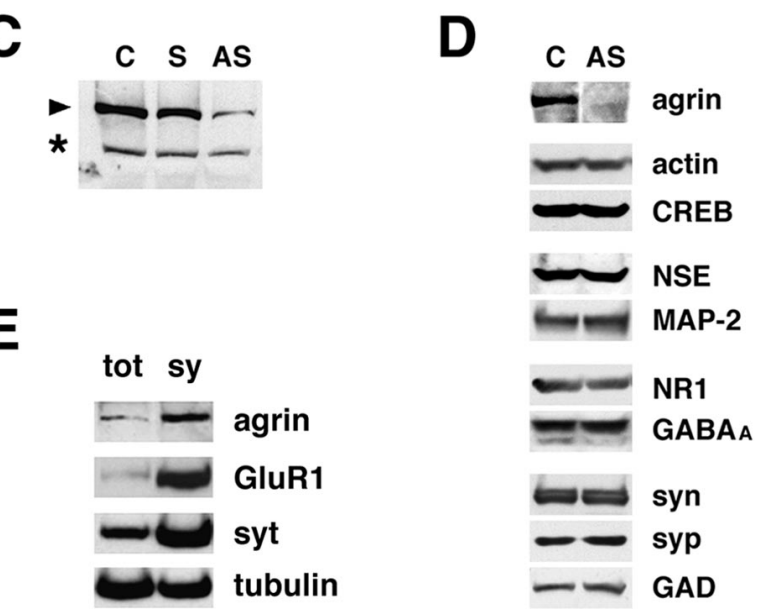

Figure 1. Specific effects of the antisense oligonucleotides on agrin expression in rat hippocampal neurons. $A$, RT-PCR analysis of agrin mRNA expression of control primary hippocampal neurons $(C)$ and after $10 \mathrm{~d}$ of treatment with sense $(S)$ and antisense $(A S)$ oligonucleotides is shown. Alternative splicing events at the $\mathrm{z}$ position were analyzed; amplified products corresponding to the isoforms Ag0, Ag8, Ag11, and Ag19 are shown. Relative glyceraldehyde-3-phosphate dehydrogenase $(G A P D H)$ amplification products are shown at the bottom. $B$, Quantification of agrin mRNA expression in control $(C)$ and in sense $(S)$ and antisense $(A S)$ oligonucleotide $(7.5 \mu \mathrm{M})$-treated cells at 2,5 , and $10 \mathrm{~d}$ in culture is shown. Agrin expression was normalized to the levels of GAPDH mRNA. Bars represent the mean \pm SEM (3 independent experiments; samples in triplicates). $C$, Antisense $(A S)$, but not sense $(S)$, oligonucleotides reduced agrin protein expression $(3 \mathrm{~d} ; 7.5 \mu \mathrm{M}$ treatment). The arrowhead indicates agrin immunoreactivity of an apparent molecular weight of $\sim 350 \mathrm{kDa}$; the asterisk indicates a nonspecific cross-reactive band. Analysis of protein extracts from postnatal (P2-P5) hippocampi revealed the same pattern of agrin immunoreactivity. The same amount of protein was loaded in each lane. $D$, The expression level of the following proteins in control $(C)$ and AS-treated $(A S)$ neurons is shown: agrin, actin, cAMP response elementbinding protein $(C R E B)$, neuronal-specific enolase (NSE), microtubuleassociated protein $2(M A P-2)$, the NMDA receptor subunit NR1, the $\beta$-chain of the GABA receptor, synapsin-I (syn), synaptophysin (syp), and glutamic acid decarboxylase $(G A D)$. Hippocampal neurons were treated for $10 \mathrm{~d}$ with $7.5 \mu \mathrm{M}$ AS oligonucleotide. The treatment substantially affected agrin expression but not the expression of the other proteins tested. $E$, Agrin immunoreactivity is enriched in synaptosomes. Ten micrograms per lane of rat hippocampus homogenate (tot) and the synaptosome preparation from rat hippocampus $(s y)$ were immunoblotted with antibodies specific for agrin (m247), the AMPA receptor subunit GluR1, synaptotagmin $(s y t)$, and tubulin. An enrichment of $>10$ of agrin immunoreactivity was observed in synaptosomes ( $n=5$ independent experiments).

ubiquitously expressed gene GAPDH (Biragyn et al., 1994). Agrin expression is presented as a percentage of the agrin/GAPDH ratio in control untreated cultures. A moderate but significant reduction $(28 \pm 8 \%$, mean $\pm \mathrm{SEM} ; p<0.01 ; n=9)$ of agrin mRNA expression was detected at as early as $2 \mathrm{~d}$ in AS-treated neurons. A much larger effect was measured at 5 and $10 \mathrm{~d}(70 \pm 4 \%$, mean \pm SEM; $p<0.01 ; n=9$; and $84 \pm 1 \%$, mean \pm SEM; $p<0.01 ; n=$ 9 , respectively) (Fig. $1 B$ ).

The overall pattern of protein expression, as detected by silver staining, was not affected by the oligonucleotide treatments. No significant changes, including changes in the amount, number, and type of proteins, were noted in extracts from control and agrin sense or antisense oligonucleotide-treated neurons (data not shown). The level of agrin protein was tested at 3 and $10 \mathrm{~d}$ of treatment by the use of Western blot analysis. Results indicate that the level of agrin expression was greatly reduced in 3-d-old cultures treated with the AS oligonucleotide but was unaffected in control and $\mathrm{S}$ oligonucleotide-treated neurons (Fig. 1C). After $10 \mathrm{~d}$ of AS treatment, agrin expression was below the level of detection (Fig. $1 D)$. The levels of expression of a transcription factor and cytoskeletal, neuronal, and synapse-specific proteins were also tested. Figure $1 D$ shows that $10 \mathrm{~d}$ of treatment with the AS oligonucleotide did not significantly affect the level of expression of any of the proteins tested.

\section{Reduced agrin expression induces changes in neuronal morphology and synaptic density}

The effects of reduced agrin expression in primary hippocampal cultures were followed over time. By $3 \mathrm{~d}$, cultures treated with antisense oligonucleotides contained multicellular aggregates with fascicles of neurites (Fig. 2A,B). Aggregates were defined as clusters of more than five cells and were detected exclusively in antisense-treated neurons ( $n \geq 50$ independent experiments). Between 3 and $14 \mathrm{~d}$, the number of cells in the clusters and the thickness of the fascicles increased. Little or no arborization of the neurites was noticed in AS-treated neurons (Fig. 2A). Similar effects were observed when cultures were exposed to either of two other antisense oligonucleotides (AS2 and ASY) (Fig. 2D; data not shown). In contrast, neurons grown in the presence of either sense (Fig. $2 A$ ) or scrambled oligonucleotides displayed morphologies indistinguishable from those of control cultures. The rate of neurite elongation did not significantly differ between control untreated and any of the oligonucleotide-treated cells (data not shown).

The degree of cell clustering and of process fasciculation depended on the concentration of antisense oligonucleotides used. Concentrations of AS oligonucleotides $<2.5 \mu \mathrm{M}$ did not produce any noticeable change. Appearance and exacerbation of the phenotype were observed at concentrations between 5 and $10 \mu \mathrm{M}$ (Fig. $2 B$ ). Decreased cell numbers could be observed in cultures treated with all of the oligonucleotides (sense, scrambled, AS, AS2, and ASY) at the highest concentrations tested $(25-30 \mu \mathrm{M})$ (data not shown).

To investigate whether treatment with agrin antisense oligonucleotides affected synapse formation in primary hippocampal neurons, we examined the appearance of punctate immunoreactivity staining of presynaptic markers, such as the synaptic vesicle proteins synaptotagmin-I, synaptophysin, and synapsin-I. This phenomenon is one of the earliest detectable events of synaptogenesis in vitro (Fletcher et al., 1991; Rao et al., 1998). To standardize the measurements among experiments, the number of synapses per neurite area was determined. Antisense oligonucleotide treatments had dramatic effects on synapse formation. The number of synapses formed depends on the amount of antisense oligonucleotide used. Concentrations between 0 and $2.5 \mu \mathrm{M}$ had small effects; $50 \%$ reduction was observed at $5 \mu \mathrm{M}$, whereas maximal effects $(\geq 90 \%$ reduction) were seen at concentrations $\geq 10 \mu \mathrm{M}$ (Fig. $2 C$ ). All three antisense oligonucleotides tested produced similar effects (Fig. 2D). All experiments described hereafter were performed, if not otherwise stated, at $7.5 \mu \mathrm{M}$ AS oligonucleotide. At this concentration, an $\sim 75-80 \%$ reduction in the number of synapses was consistently observed without any detectable decrease in cell number (Fig. 2).

NMDA receptor clustering precedes synapse formation in primary hippocampal neurons (Rao and Craig, 1997; Rao et al., 1998). Microclusters of NMDA receptors are present on dendrites, proximal to the perikarya, as early as day 2 in vitro but become localized at synapses, even at considerable distance from the cell bodies, after $10 \mathrm{~d}$. To test whether this specific arrangement of NMDA receptors depends on the expression of agrin, we determined the pattern of immunoreactivity in AS-treated hippocampal neurons of the NMDA receptor subunit NR1. All subtypes of NMDA receptors contain this particular subunit. Neither the number nor the localization of the NR1-immunoreactive puncta in relation to the 


\section{A}

Figure 2. Agrin antisense oligonucleotides induced a change in phenotype in rat hippocampal neurons. $A$, Morphology of cultured neurons at $3 \mathrm{~d}(3 d), 7 \mathrm{~d}(7 d)$, and $14 \mathrm{~d}(14 d)$ in culture. Only neurons treated with the agrin antisense oligonucleotide AS appeared clustered in multicellular aggregates with extended neurites in fascicles. All three antisense oligonucleotides tested produced the same phenotype. The concentration of $\mathrm{S}(S)$ and AS $(A S)$ oligonucleotides was $7.5 \mu \mathrm{M}$. Scale bar, $100 \mu \mathrm{m}$. $B$, Concentration dependence of the AS oligonucleotides. The severity of the phenotype described in $A$ increases with increasing concentration of AS oligonucleotides. Decreased cell numbers were observed in cultures treated with all three AS oligonucleotides tested at concentrations $\geq 25 \mu \mathrm{M}$. Scale bar, $60 \mu \mathrm{m}$. $C$, Determination of the concentration-response curve of the AS oligonucleotide for synaptic differentiation. Synapsin-I-immunoreactive puncta per neurite area were measured in hippocampal neurons treated for $10 \mathrm{~d}$ with the AS oligonucleotide ( $A S$ oligo). Mean \pm SEM values (synapses on $n=20$ neurites in 5 randomly chosen fields) of a representative experiment $(n=$ 3 independent experiments) are shown. $D$, Quantification of the number of synapsinI-immunoreactive puncta per neurite area in cultured hippocampal neurons treated for $10 \mathrm{~d}$ with $5 \mu \mathrm{M}$ agrin sense $(S)$, scrambled (SC), and three agrin antisense oligonucleotides ( $A S, A S 2$, and $A S Y$ ). Mean \pm SEM values of a representative experiment ( $n=3$ independent experiments) are shown $(n=20$ neurites in 5 randomly chosen fields of view/treatment; $p<0.05)$. Control cultures $(C)$.
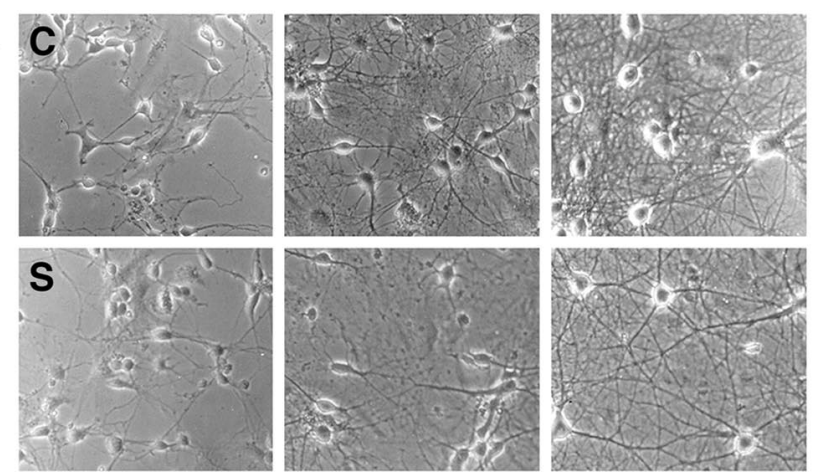

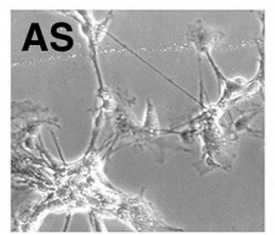

3d

B

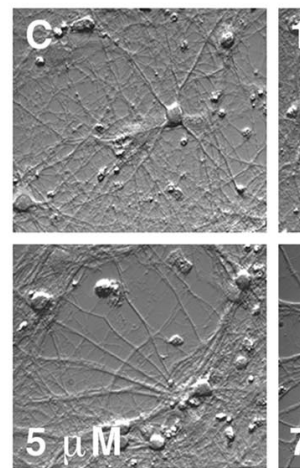

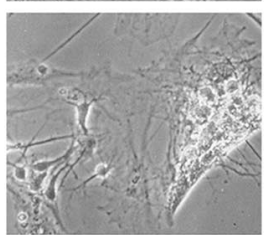

$7 d$

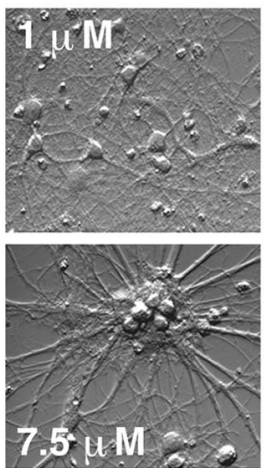

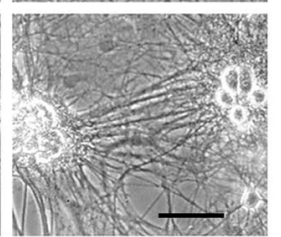

14d

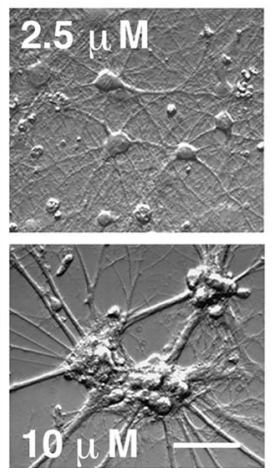

C

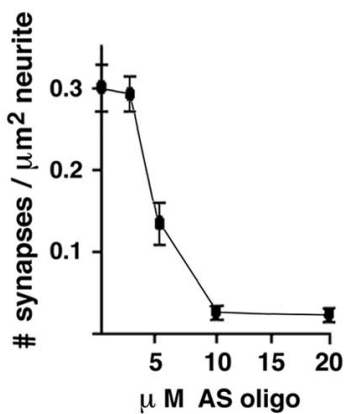

D

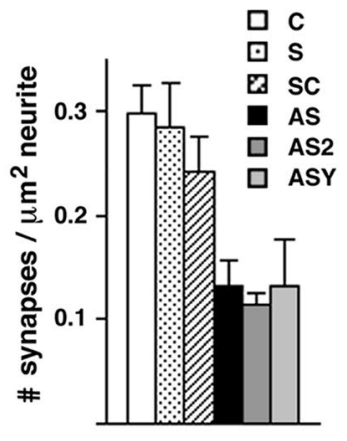

cell soma changed in neurons treated for $10 \mathrm{~d}$ with AS oligonucleotides (Fig. 3c, $c^{\prime}$ ), suggesting that agrin is not necessary for the initial clustering of NMDA receptors.

The differentiation of mature synapses is accompanied by the specific association of cytosolic and cytoskeletal molecules to postsynaptic proteins. The postsynaptic molecule synGAP is a component of a multimeric complex that includes NMDA receptors (Chen et al., 1998; Kim et al., 1998). We tested whether the synaptic localization of synGAP is affected by the agrin antisense oligonucleotide treatment. In contrast to NMDA receptors, treatment with AS oligonucleotides for $10 \mathrm{~d}$ completely abolished the punctate pattern of synGAP immunoreactivity (Fig. $3 b, b^{\prime}$ ). This suggests that synGAP associates with the NMDA receptors only after synapses have formed, which is consistent with the developmental pattern of expression of these two proteins (Chen et al., 1998; Kim et al., 1998).

\section{Agrin antisense oligonucleotide treatment does not alter the morphology and the synaptic density of agrin- deficient neurons}

Our data indicate that reduction of agrin expression strongly affects synaptic differentiation in vitro. However, this is in contrast to results obtained from hippocampal and cortical neurons from agrin-deficient mice in which the morphological and functional development of synapses appeared normal (Li et al., 1999; Serpinskaya et al., 1999). We reasoned that if the agrin antisense oligonucleotides affected wild-type neurons in a specific manner (i.e., by reducing agrin expression), they should not elicit the same phenotype in neurons from agrin-deficient mice. Therefore, embryonic day 17 hippocampal neurons obtained from wild-type, agrinheterozygous, and agrin-deficient mice were treated for various times with the AS oligonucleotide. The treatment equally affected wild-type and agrin-heterozygous murine and postnatal rat neu- rons (Fig. 3a, $a^{\prime}, d, d^{\prime}$ ) but did not affect agrin-deficient neurons; untreated or AS-treated agrin-deficient neurons showed the same morphology and synaptic density (determined with antibodies for the presynaptic markers synaptophysin, synapsin-I, and synaptotagmin-I) (Fig. 3e, $e^{\prime}$; data not shown). These results indicate that the antisense oligonucleotide treatments affected neurons specifically by reducing agrin expression and did not have generalized cytopathic effects.

Surprisingly, when the pattern of immunoreactivity for synGAP was studied in neurons obtained from agrin-deficient mice, a striking difference was detected between 13- and 24-d-old untreated cultures. At $13 \mathrm{~d}$, distinct immunoreactive puncta were visible both in wild-type and agrin-deficient neurons (Fig. 3f,g). However, punctate synGAP immunoreactivity was no longer detectable in 24-dold agrin-deficient neurons $(89 \pm 2 \%$ reduction compared with control wild-type neurons, mean \pm SEM; $p<0.01 ; n=10$ ) (Fig. $\left.3 f^{\prime}, g^{\prime}\right)$.

\section{Incubation of neurons with an agrin-specific antibody produces synaptic alterations similar to those produced by agrin antisense oligonucleotides}

It was shown previously that anti-agrin antibodies prevent the formation of neuromuscular junctions in vitro (Cohen and Godfrey, 1992; Reist et al., 1992). Therefore, we tested whether agrinspecific antibodies inhibit synaptic differentiation in hippocampal neurons. We used an agrin-specific monoclonal antibody (m247) that recognizes an epitope close to the z-site and that greatly reduces the AChR-aggregating activity of agrin (Hoch et al., 1994). The number of synapsin-I-immunoreactive puncta was dramatically reduced $(83 \pm 2 \%$, mean $\pm \mathrm{SEM} ; p<0.05 ; n=15$ fields of view, 3 independent experiments) in 10-d-old neurons treated from the onset of the culture with the $\mathrm{m} 247$ antibody (Fig. 4A,B). Incubation with control antibodies did not affect synaptic differen- 

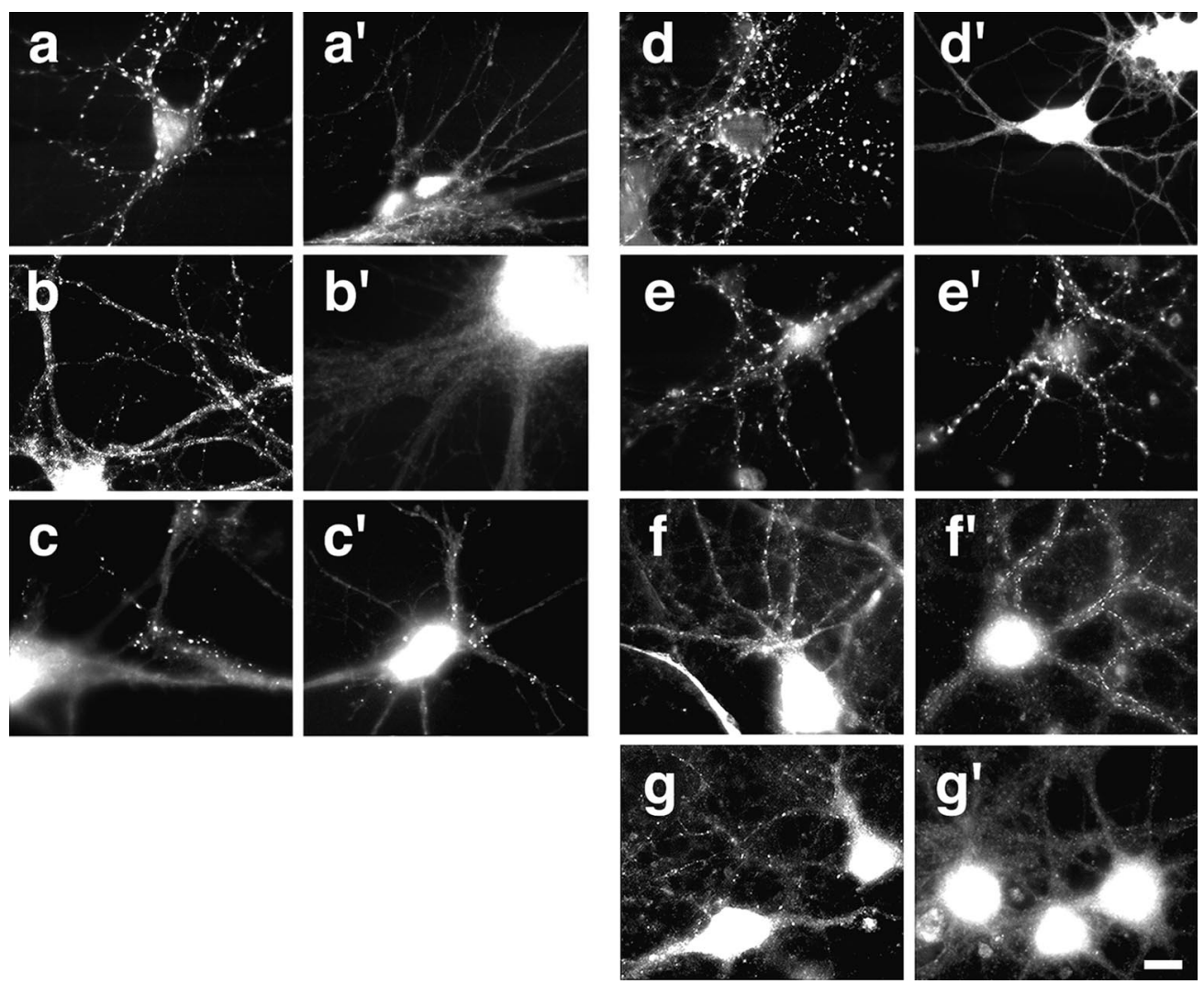

Figure 3. Effects of the antisense oligonucleotide treatment on wild-type and agrindeficient neurons. Immunocytochemical analysis of synaptic differentiation in 10-dold, antisense oligonucleotide-treated hippocampal neurons. $a-c^{\prime}$, Rat (P3-P5) hippocampal neurons were treated with 7.5 $\mu \mathrm{M}$ AS oligonucleotides. Patterns of immunoreactivity are shown for synapsin-I $(a$, $\left.a^{\prime}\right)$, synGAP $\left(b, b^{\prime}\right)$, and the NMDA receptor subunit NR1 $\left(c, c^{\prime}\right)$. The treatment with the AS oligonucleotides affected the synapsin-I and synGAP staining but not the NR1 immunoreactivity. $d-e^{\prime}$, E18 mouse hippocampal neurons were treated for $10 \mathrm{~d}$ with $7.5 \mu \mathrm{M}$ AS oligonucleotides. Synapsin-I immunoreactivity is shown in untreated $(d, e)$ and treated $\left(d^{\prime}, e^{\prime}\right)$ neurons. Synapsin-I-immunoreactive puncta disappeared in AS-treated wild-type $\left(d^{\prime}\right)$ but not in AS-treated agrin-deficient $\left(e^{\prime}\right)$ neurons. $f-g^{\prime}$, synGAP staining in wildtype $\left(f, f^{\prime}\right)$ and agrin-deficient $\left(g, g^{\prime}\right)$ E18 hippocampal neurons is shown. Cultures were maintained for $13 \mathrm{~d}(f, g)$ and $24 \mathrm{~d}$ $\left(f^{\prime}, g^{\prime}\right)$. Although synGAP puncta disappeared in mutant neurons between 13 and $24 \mathrm{~d}$, they were still observed in wild-type neurons. The pattern of synapsin-I immunoreactivity did not change during this time period (data not shown). Scale bar, 20 $\mu \mathrm{m}$.

tiation. Interestingly, the treatment with the agrin-specific antibody was effective in preventing synaptic differentiation but did not produce the aggregation of cell bodies and the fasciculation of processes that were seen with the agrin antisense oligonucleotides. To investigate further the relationship between the synaptic differentiating activity of agrin and the adhesive properties of the substrate, we treated neurons plated on laminin-coated coverslips with the antisense oligonucleotides. Surprisingly, the AS oligonucleotide $(7.5 \mu \mathrm{M})$ produced the same effects as did the anti-agrin antibody treatment: synaptic differentiation was inhibited without changes in cell or process morphology (data not shown).

\section{Recombinant agrin rescues the changes induced by antisense oligonucleotides}

Using soluble recombinant agrin, we then tested whether specific isoforms differentially reversed the effects of the agrin antisense oligonucleotide treatment. The Ag4,0 and Ag4,8 have 100- to 1000 -fold differences in their AChR-aggregating activity and also have different abilities to induce pCREB in hippocampal neurons (Bowen et al., 1996; Ji et al., 1998). Therefore, hippocampal neurons were treated for $10 \mathrm{~d}$ with $7.5 \mu \mathrm{M}$ AS oligonucleotides and with $\sim 50$ pm purified $\mathrm{Ag} 4,0$ or Ag4,8 isoforms. AS oligonucleotidetreated neurons incubated with the $\mathrm{Ag} 4,8$, but not the $\mathrm{Ag} 4,0$, isoform had a much larger $(>90 \%)$ number of synapsin-Iimmunoreactive puncta compared with AS-treated neurons (Fig. $4 C, D)$. Interestingly, the incubation with the $\mathrm{Ag} 4,8$ isoform also reversed the morphological changes (clustering of cell bodies and fasciculation of processes) induced by the AS treatment. These results indicate that the $\mathrm{Ag} 4,8$ isoform is able to induce synaptic differentiation in AS-treated hippocampal neurons, thus confirming that the effects of the agrin antisense oligonucleotide treatments were caused by a reduction in agrin expression.

\section{Ultrastructural analysis of synapses formed in primary hippocampal neurons expressing low levels of agrin}

To study the ultrastructural morphology of synapses when agrin expression was strongly reduced, we analyzed and compared serial sections from untreated and from agrin sense and antisense oligonucleotide-treated neurons by electron microscopy. After $15 \mathrm{~d}$ in culture, synapses present in untreated neurons displayed a fully mature ultrastructural phenotype, as reported previously (Forti et al., 1997). Synapses formed in the presence of either sense ( $\mathrm{S} ; n=$ 243 ) or antisense (AS; $n=285$ ) oligonucleotides were morphologically indistinguishable from terminals in untreated cultures $(n=$ 310). However, the number of synapses was dramatically reduced in AS-treated cultures. As for untreated neurons, most synapses analyzed in sense and antisense oligonucleotide-treated neurons were localized on spiny extroflexions from dendrites (Papa et al., 1995). Dendritic shafts could be easily identified by the presence of numerous mitochondria and microtubules. Synapses on the dendritic shaft could also be found (Fig. 5). Presynaptic terminals displayed a large pool of available vesicles $\left(n_{\text {vesicles }}=57 \pm 25\right.$ per section, mean \pm SD). Approximately $15 \%$ of these vesicles appeared to be docked at the active zones (Fig. 5). Most presynaptic varicosities $(85 \%)$ were found juxtaposed to membranes containing electron-dense PSDs (Fig. 5, top row; type I synapses). This type of synapse invariably contained a single PSD, which could be observed across a series of sections. The remaining synapses $(\sim 15 \%)$, without detectable PSDs (Fig. 5, bottom row; type II synapses), were presumably inhibitory. These results confirm that puncta seen by immunofluorescence staining with synaptic markers represent differentiated synapses.

\section{Low levels of agrin expression inhibit spontaneous and evoked synaptic transmission}

To characterize further the phenotype of synapses established by hippocampal neurons expressing low levels of agrin, synaptic function was analyzed. Evoked and spontaneous transmission was monitored in individual neurons by patch-clamp recording in the wholecell configuration. Evoked responses were elicited with $0.2 \mathrm{~Hz}$ stimulation using a glass electrode filled with physiological saline placed on the cell soma of nearby neurons. The probability of detecting a pair of synaptically connected neurons in both untreated and agrin sense oligonucleotide-treated cultures was comparable $(\sim 40 \%)$. In these cultures, the average evoked currents 
Figure 4. Treatment with an agrin-specific antibody prevented synaptic differentiation; recombinant agrin countered the effects of the antisense oligonucleotides in hippocampal neurons. $A$, Rat P3-P5 hippocampal neurons were plated in the presence of the m 247 antibody. Cultures were kept for $10 \mathrm{~d}$. Immunofluorescence staining for synapsin-I was performed on untreated (Untr; a cluster of 3 neurons is shown) and $\mathrm{m} 247$-treated $(\alpha A g A b)$ cultures. The number of synapsin-Iimmunoreactive puncta was greatly reduced in the treated neurons. Treatment with an unrelated antibody did not produce any phenotype (data not shown). Scale bar, $50 \mu \mathrm{m}$. B, Quantification of the effects of the m247 antibody on synaptic differentiation is shown. The number of synapsin-I-immunoreactive puncta per neurite area was greatly reduced $(\geq 80 \%)$ in treated cells $(\alpha A g A b)$ compared with untreated (Untr) and mock antibodytreated $(C)$ cells. Values are from a representative experiment $(n=3)$; mean \pm SEM values were calculated from 20 fields of view $(p<0.01)$. $C$, Neurons were incubated with antisense oligonucleotides and purified recombinant agrin isoforms. P3-P5 rat hippocampal neurons were treated for $10 \mathrm{~d}$ with the AS oligonucleotide $(10 \mu \mathrm{M})$ with either the Ag4,0 or $\mathrm{Ag} 4,8$ isoforms (50 pM). Immunofluorescence staining with synapsin-I-specific antibodies is shown for untreated (Untr), AS-treated $(A S), \mathrm{AS}$ and $\mathrm{Ag} 4,0$-treated $(A S / A g 0)$, and $\mathrm{AS}$ and $\mathrm{Ag} 4,8$-treated $(A S /$ Ag8) neurons. Only the cultures treated with the $\mathrm{Ag} 4,8$ isoforms appeared similar to control untreated cells. $D$, Quantifica-

tion of the effects of the antisense oligonucleotide and agrin isoform treatment is shown. The number of synapses per neurite area was determined for 10-d-untreated (Untr), AS-treated $(A S)$, AS and Ag4,0-treated $(A S / A g 0)$, and AS and Ag4,8-treated $(A S / A g 8)$ neurons. Mean \pm SEM values $(n=20$ neurites in 5 randomly chosen fields of view per treatment; $p<0.05)$ are shown from a representative experiment $(n=4$ independent experiments). Scale bar, $40 \mu \mathrm{m}$.
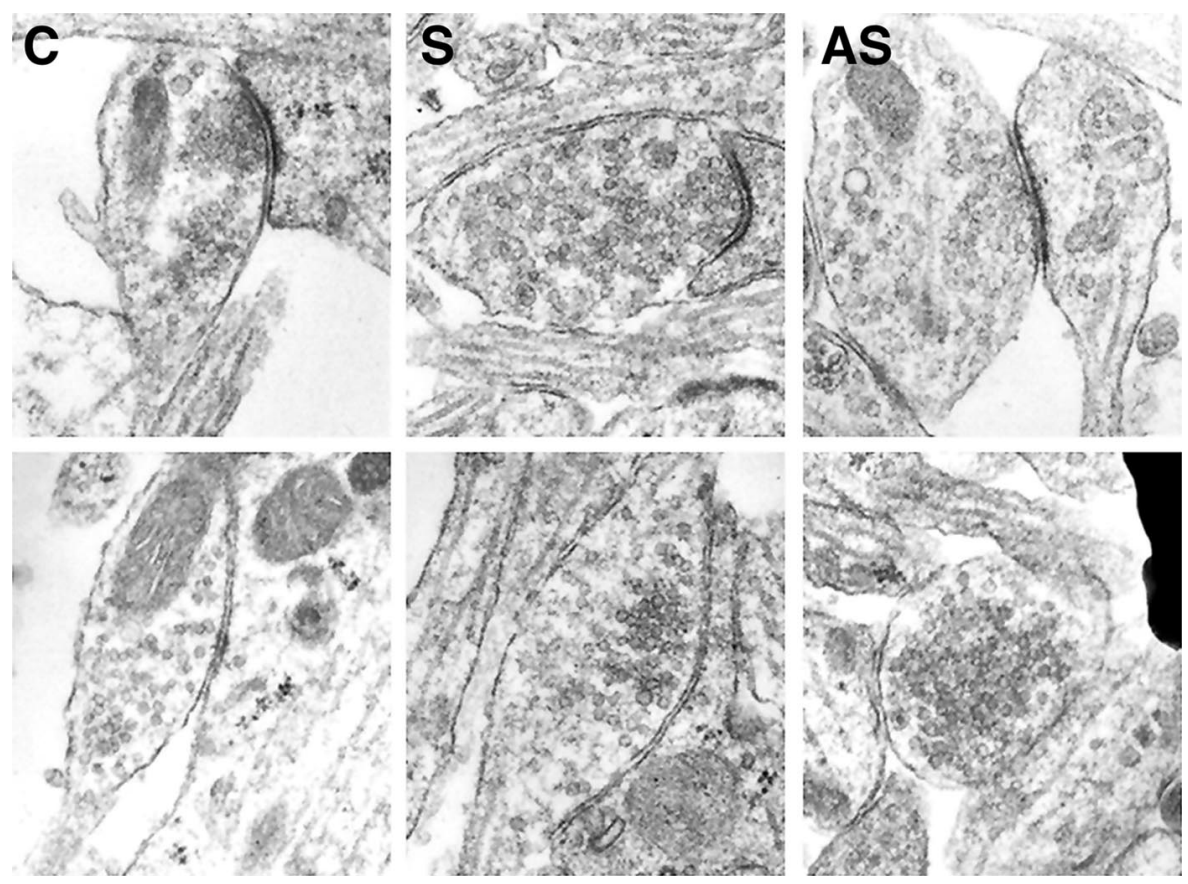

Figure 5. Ultrastructural morphology of synapses formed at low levels of agrin expression. The two major types of morphologically distinct synapses present in the P3-P5 rat hippocampal cultures are shown in untreated $(C)$ and in sense $(S)$ - and antisense (AS)-treated neurons. Top row, Type I synapses with distinct postsynaptic densities. Bottom row, Type II synapses (presumably inhibitory) without postsynaptic densities. No noticeable changes in morphology were observed between untreated and treated neurons. The frequency of type I and II synapses was similar in all experimental conditions $(\sim 85$ and $15 \%$, respectively). exceeded $200 \mathrm{pA}(I=224 \pm 30 \mathrm{pA}$, mean $\pm \mathrm{SEM} ; n=12)$, and transmission failures were very low (Fig. 6). In cultures treated with agrin antisense oligonucleotides (AS), the stimulation of neighboring neurons produced detectable current in only $3 \%$ of the postsynaptic neurons tested. In these instances, transmission failures were high ( $83 \%$ transmission failure; $n=6$ successful recordings), and the amplitude of the response was small $(I=52 \pm 14 \mathrm{pA}$, mean \pm SEM) as shown in Figure 6, $A$ and $C$.

Analyses of minis provide important information on the synaptic physiology of evoked responses. Therefore, minis were recorded from neurons treated with AS oligonucleotides in the presence of TTX (1 $\mu \mathrm{M})$. Distinct minis were detected in AS oligonucleotide- 

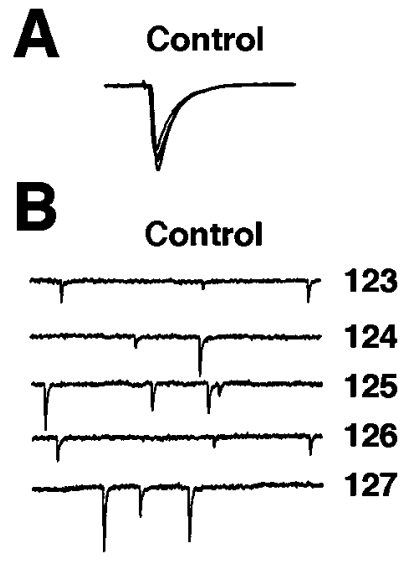

C

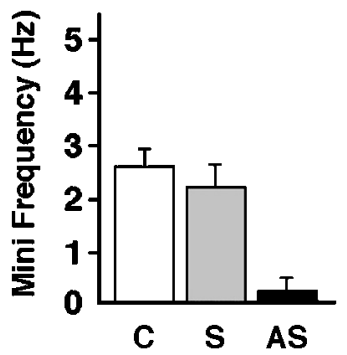

B
Antisense

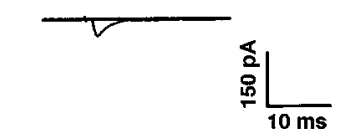

Antisense
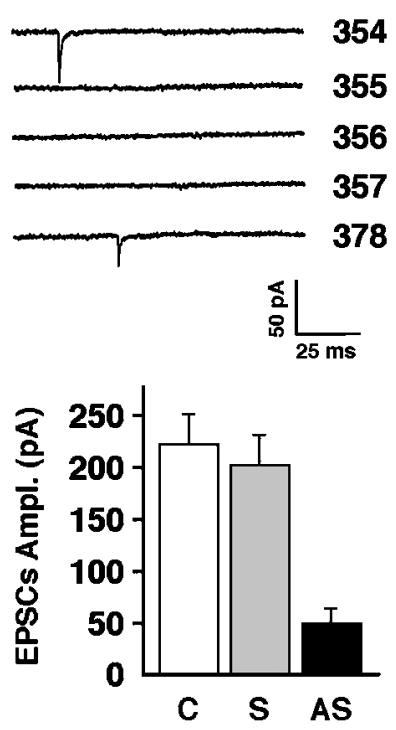

Figure 6. Low levels of agrin expression affect minis and evoked responses in hippocampal neurons. $A$, Representative examples of excitatory currents evoked by action potentials in neurons treated with agrin sense (control) (left $)$ or antisense (right) oligonucleotides $(\mathrm{Vm}=-60 \mathrm{mV}) . B$, Miniature events recorded from control (left) and antisense oligonucleotide-treated (right) neurons in the presence of TTX. Sweep numbers are shown on the right of the corresponding traces. In the antisense traces, only two minis were detected between sweeps 354 and 378. C, Quantification of the effects of the oligonucleotide treatments on the frequency of minis [left; data from $n=$ 12, 7, and 10 experiments for control $(C)$, sense $(S)$, and antisense $(A S)$ conditions, respectively] and the amplitude of the evoked EPSCs (right; data from $n=12,8$, and 6 experiments for control, sense, and antisense conditions, respectively) (mean \pm SEM).

treated neurons although their frequency was dramatically reduced compared with that of untreated neurons (91\% reduction; $n=12$ control and 10 AS-treated recordings; $p<0.05$ ) (Fig. 6B,C). The amplitude of the minis seemed unaffected $\left(I_{\text {control }}=22.8 \pm 5.1 \mathrm{pA}\right.$; $I_{\mathrm{AS}}=26.3 \pm 7.4 \mathrm{pA}$, mean $\pm \mathrm{SEM}$ ) although the small number of events did not allow a more careful evaluation of this parameter.

The reduced number of synapses in the AS-treated cultures could account for the conservation of the quantal size, the decreased frequency of minis, and the reduced amplitude of evoked responses in pairs of electrically connected neurons. However, the magnitude of the observed decrease in these responses (91 and $83 \%$, respectively) appears to be larger than the decrease in the number of synapses induced by the AS treatment $(\sim 75 \%$ at 7.5 $\mu \mathrm{M})$. This discrepancy could be explained by either a relative increase of silent synapses (Feldman and Knudsen, 1998) or a reduced probability of release at presynaptic terminals. Electrophysiological analysis cannot easily differentiate between presynaptic and postsynaptic phenomena, and the number of synapses contributing to the response on a particular neuron is difficult to estimate.

\section{Reduced agrin expression inhibits exo-endocytosis of synaptic vesicles}

The results presented above suggest that low levels of agrin expression affect the function of presynaptic terminals. Therefore, we have measured the rate of spontaneous exocytosis at hippocampal synapses using antibodies as described previously (Matteoli et al., 1992; Malgaroli et al., 1995). This method allows us to quantify differences in synaptic vesicle turnover independently from postsynaptic responses. Briefly, living neurons were incubated with antibodies specific for the intralumenal domain of synaptotagmin-I for $1 \mathrm{hr}$ in the presence of TTX $(1 \mu \mathrm{M})$. The cells were then fixed and incubated with a second antibody specific for the cytosolic portion of synaptotagmin-I, which was raised in a species different from that used for the first antibody. Species-specific secondary antibodies, coupled with different fluorochromes, were used to determine the extent of exo-endocytosis at individual synapses (revealed by the internalized antibody) versus the total number of synapses (detected by the second synaptotagmin-I antibody). The data were analyzed by confocal fluorescence microscopy and expressed as arbitrary units of intensity. Most synapses in untreated or agrin sense oligonucleotide-treated neurons showed uptake of anti-synaptotagmin-I antibody $(n=15$ experiments; $p<0.05)$, with individual synapses revealing variable levels of uptake. However, no significant difference in the mean uptake was detected between the two experimental groups (Fig. 7). In agrin antisense oligonucleotide-treated neurons, the number of synapses was drastically reduced $(76 \%$ reduction; $5-10$ fields/condition analyzed in $n=10$ experiments; $p<0.05$ ). Furthermore, the remaining synapses displayed a marked reduction in the number of cycles of exo-endocytosis (Fig. 7). Thus, the reduction in the number of synapses combined with their diminished capability to release quanta could explain the decrease in synaptic responses detected in neurons treated with AS oligonucleotides.

\section{DISCUSSION}

Evidence is presented here in support of the hypothesis that agrin is necessary for synaptogenesis in hippocampal neurons. Reducing agrin expression with antisense oligonucleotides or blocking agrin function with antibodies greatly reduced synapse formation in these neurons. A specific synaptic change occurs over time in neurons obtained from agrin-deficient mice.

Three possible interpretations are compatible with our observations. First, it has been proposed that agrin functions as an adhesion molecule (Campagna et al., 1995; Chang et al., 1997) and that cell adhesion molecules regulate synapse formation and plasticity (Davis and Goodman, 1998; Hoffman, 1998). Consistent with this model is the appearance of multicellular aggregates and fasciculated processes in hippocampal cultures when agrin expression is reduced, suggesting that agrin affects cell-substrate adhesion. However, blocking agrin function with agrin-specific antibodies, or reducing agrin expression with antisense oligonucleotides in neurons plated onto laminin, inhibited synaptic differentiation without the induction of morphological changes. This suggests that diminished cell-substrate adhesion of neurons expressing low levels of agrin is not the reason underlying their inability to form synapses. In the case of the antibody experiments, however, it is possible that agrin molecules involved in cell-substrate adhesion are less accessible to the antibodies than are those mediating synapse formation (localized at cell-cell adhesion sites). Alternatively, the antibody treatment may be only partially effective in blocking agrin function, implying that agrin-mediated synapse formation and adhesion require different thresholds of agrin expression.

Second, agrin may affect synaptogenesis by controlling neural differentiation. One possibility is that agrin regulates gene transcription. In agreement with this hypothesis are results indicating that agrin regulates gene expression in muscles (I. Cohen et al., 1997; Jones et al., 1997; Meier et al., 1997; Gramolini et al., 1998) and cortical neurons (Hilgenberg et al., 1999) and that specific agrin isoforms activate the transcription factor CREB in hippocampal neurons (Ji et al., 1998). Another possibility, because agrin is an heparan sulfate proteoglycan, is that it binds differentiation factors (Tsen et al., 1995; Halfter et al., 1997). Agrin binds basic fibroblast growth factors (bFGFs) and pleiotrophin and heparin-binding, growth-associated molecule (Daggett et al., 1996; Cotman et al., 1999). In some cases, such as bFGF, binding to proteoglycans is necessary for the activation of specific receptors (Klagsbrun and Baird, 1991). Also, the N-terminal region of agrin contains domains homologous to Kazal-type serine protease inhib- 
A
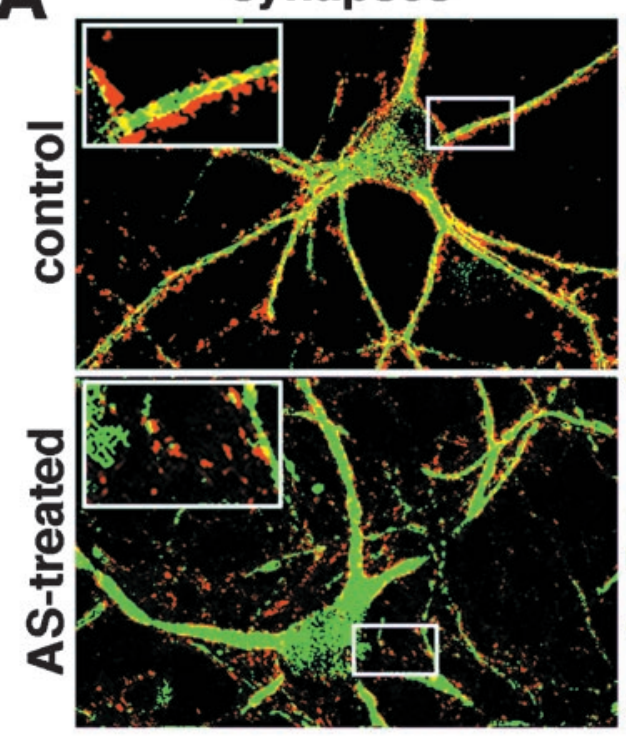

synapses
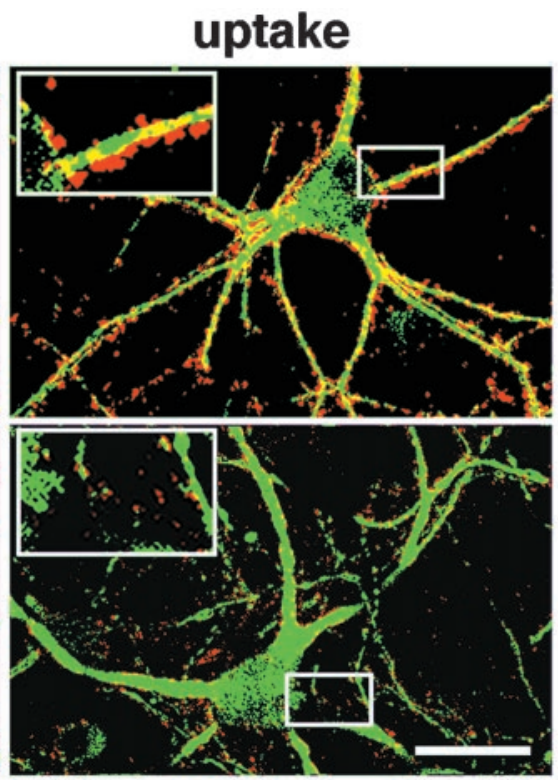

B
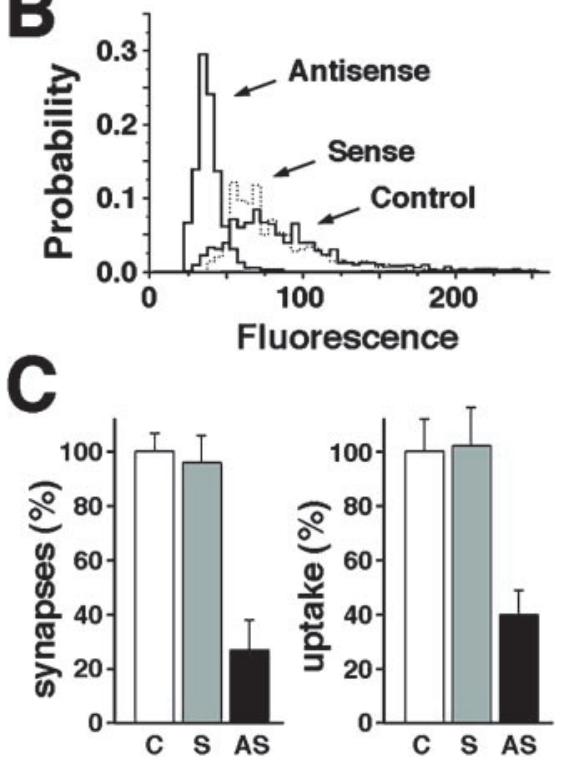

Figure 7. Reduction of synaptic vesicle turnover in hippocampal neurons expressing low levels of agrin. $A$, Triple confocal immunofluorescence staining was performed using different excitation/emission channels as described in Materials and Methods. Dendrites are depicted in green (corresponding to MAP-2 immunoreactivity). Left, Synapses in control and AS-treated neurons are shown in red (Cy5-coupled secondary antibody; $680 \mathrm{~nm}$ emission). Right, Spontaneous vesicular turnover at individual synapses also is depicted in red (Texas Red-coupled antibodies; $568 \mathrm{~nm}$ emission). The AS oligonucleotide treatment not only reduced the number of synapses but also the exo-endocytic cycling of vesicles occurring at individual synapses. $B$, Distributions of probability for the antibody internalization (in arbitrary units of fluorescence) at individual synapses from a representative experiment are shown. Note the similar degree of exo-endocytosis in control $(n=850$ boutons $)$ and sense-treated cultures $(n=659$ boutons $)$ versus that in antisense-treated cultures ( $n=389$ boutons). $C$, Percentage of synapses (left $)$ and percentage synaptic uptake (right) from control $(C)$ and agrin sense $(S)$ - or antisense $(A S)$-treated cultures (mean \pm SEM; $n=15$ experiments) are shown. All incubations with living hippocampal neurons were performed in the presence of TTX (1 $\mu \mathrm{M})$ and APV $(25 \mu \mathrm{M})$. Values are indicated as a percentage of control levels.

itors, which are also found in follistatin and osteonectin/SPARC/ BM-40 (Rupp et al., 1992; Patthy and Nikolics, 1993). Follistatin and osteonectin bind the differentiation factor activin and plateletderived growth factor, respectively (Patthy and Nikolics, 1993). In the case of follistatin, this binding prevents the interaction of activin with its receptor (Hemmati-Brivanlou et al., 1994). Therefore, agrin may control neuronal differentiation either by facilitating or by impeding the function of differentiation factors.

Third, agrin may activate specific signaling events that lead to clustering and targeting of synaptic molecules. In fact, the activation of receptor tyrosine kinases is required for the agrin-mediated clustering of AChR at NMJs (Wallace, 1984; DeChiara et al., 1996; Ferns et al., 1996) and for CREB phosphorylation in hippocampal neurons (Ji et al., 1998). Because only the $\mathrm{Ag} 4,8$ isoform is able to restore synaptogenesis in antisense-treated neurons and to induce CREB phosphorylation, these two functions may be related. Although our results demonstrate the importance of specific agrin isoforms for synapse formation in hippocampal neurons, they do not resolve the mechanism of agrin function.

A surprising observation is that addition of recombinant soluble agrin isoforms to hippocampal neurons expressing normal levels of agrin does not affect presynaptic or postsynaptic differentiation (Serpinskaya et al., 1999) (C. M. Böse, unpublished observations). Moreover, hippocampal neurons are not competent to function as postsynaptic targets for 3-4 d in vitro (Fletcher et al., 1994). One possible explanation is that agrin cannot induce synaptic differentiation in "young" neurons because they do not yet express molecules needed for the recruitment, stabilization, or targeting of synaptic molecules. After synapses have been established, however, the majority of the molecules required to form synaptic specializations may have accumulated at or been preferentially targeted to those synapses. Thus, despite the activation of the correct receptormediated signaling cascade by recombinant agrin, the concentration of synaptic molecules localized at extrasynaptic sites may be too low to form immunocytochemically detectable structures. Alternatively, the addition of agrin to mature neurons may increase the density of presynaptic and postsynaptic molecules at preexist- ing synapses. This process could also be technically difficult to evaluate. Lastly, it may be that contact between presynaptic and postsynaptic terminals is necessary for the stabilization of synaptic molecule aggregates in hippocampal neurons.

The shape of the concentration-response curve of the antisense oligonucleotide treatment suggests that a threshold of agrin expression exists above which synapse formation may proceed. However, synapses established at intermediate or low levels of agrin expression may either belong to a specific type, whose formation does not depend on agrin, or be established by a specific class of neurons. Both interpretations are unlikely because these synapses are morphologically heterogeneous and appeared evenly distributed throughout the cultures. These synapses appear indistinguishable, at the ultrastructural level, from control untreated synapses, even though their spontaneous and evoked release probabilities are diminished. Therefore, we conclude that reaching the critical threshold of agrin expression may not be sufficient to complete synaptic differentiation. It will be interesting to determine whether the formation of specific types of synapses requires different levels of agrin expression or whether the synaptic localization of ion channels or subtypes of neurotransmitter receptors occurs at different thresholds of agrin expression.

The initial phase of synapse formation in agrin-/- neurons seems to occur normally in vitro (Li et al., 1999; Serpinskaya et al., 1999). This argues for the existence of functional redundancy for agrin, which is further supported by our data showing that the treatment of agrin-/- neurons with agrin antisense oligonucleotide does not prevent synapse formation. How can the data presented here be reconciled with the idea of functional redundancy? It is possible that when agrin expression is absent from the onset of neurogenesis, neurons may be able to induce the expression of compensatory alternatives. If their cellular and molecular environment mediates this regulation, then this will probably not occur in vitro. Our data are consistent with this model: wild-type neurons are unable to express compensatory mechanisms when agrin expression is reduced in vitro, and agrin-deficient neurons cultured for $>24 \mathrm{~d}$ show a specific synaptic change, suggesting that they 
gradually loose their ability to compensate for agrin. Among possible compensatory molecules are adhesion molecules and synaptic differentiation factors. Laminin is a likely candidate. Approximately $25 \%$ of the agrin polypeptide is homologous to regions in laminin subunits, and laminin can induce the aggregation of AChR on myotubes, although at high concentrations and via different mechanisms than seen with agrin (M. W. Cohen et al., 1997; Sugiyama et al., 1997; Montanaro et al., 1998). Moreover, laminin and agrin bind $\alpha$-dystroglycan, and a specific pattern of laminin immunoreactivity can be detected at NMJs and synaptic spines in hippocampal neurons (Sanes et al., 1990; Tian et al., 1997). In addition, agrin functions in part via the activation of integrins (Martin and Sanes, 1997; Burkin et al., 1998). However, laminin is not able to compensate for agrin when functioning as a cellsubstrate adhesion molecule. It will be interesting to determine whether this is also true for other laminin isoforms. Recent results indicate that the secreted lectin neuronal activity-regulated pentraxin (Narp) satisfies many conditions of a synaptic differentiation factor (Tsui et al., 1996; O'Brien et al., 1999). Although Narp seems to regulate the synaptic localization of a specific subset of glutamate receptors, it has not yet been determined whether it is indeed required for the clustering of glutamate receptors and/or for synapse formation (O'Brien et al., 1999). Lastly, if the role of agrin is to bind and/or present synaptic differentiation factors to specific receptors, than the expression of other proteoglycans may also compensate for agrin.

The results of a recent study suggest, in contrast to our observations, that reduced agrin expression in hippocampal neurons cultured with monolayers of astroglial cells affected primarily GABAergic synapses (Ferreira, 1999). This raises the interesting possibility that astroglia also secrete factors able to compensate for agrin activity.

The localization of the postsynaptic molecule synGAP is affected in antisense oligonucleotide-treated and agrin $-/-$ neurons. The role of synGAP is still undetermined. Because synGAP puncta appear at later stages of synaptogenesis (Kim et al., 1998), it will be interesting to test aspects of synaptic transmission, including plasticity, in neurons displaying aberrant synGAP localization.

In conclusion, our results show that agrin is necessary for the induction of synaptic differentiation in primary hippocampal neurons. Further investigations will be needed to study the role of all agrin isoforms in the development of the CNS, to determine when and for how long cultured neurons become competent to respond to agrin, and to study the kinetics of the agrin-mediated responses. This information will be useful for designing approaches to isolate the neuronal agrin receptor(s). Moreover, the elucidation of the molecular mechanisms underlying agrin's function and/or the identification of the compensatory mechanisms for agrin may reveal other factors required for synapse formation.

\section{REFERENCES}

Biragyn A, Arkins S, Kelley KW (1994) Riboprobe expression cassettes for measuring IGF-I, beta-actin and glyceraldehyde 3-phosphate dehydrogenase transcripts. J Immunol Methods 168:235-244.

Bowen DC, Sugiyama J, Ferns M, Hall ZW (1996) Neural agrin activates a high-affinity receptor in $\mathrm{C} 2$ muscle cells that is unresponsive to muscle agrin. J Neurosci 16:3791-3797.

Burgess RW, Nguyen QT, Son YJ, Lichtman JW, Sanes JR (1999) Alternatively spliced isoforms of nerve- and muscle-derived agrin: their roles at the neuromuscular junction. Neuron 23:33-44.

Burkin DJ, Gu M, Hodges BL, Campanelli JT, Kaufman SJ (1998) A functional role for specific spliced variants of the alpha7beta1 integrin in acetylcholine receptor clustering. J Cell Biol 143:1067-1075.

Campagna JA, Ruegg MA, Bixby JL (1995) Agrin is a differentiationinducing "stop-signal" for motoneurons in vitro. Neuron 15:1365-1374.

Campagna JA, Ruegg MA, Bixby JL (1997) Evidence that agrin directly influences presynaptic differentiation at neuromuscular junctions in vitro. Eur J Neurosci 9:2269-2283.

Campanelli JT, Gayer GG, Scheller RH (1996) Alternative RNA splicing that determines agrin activity regulates binding to heparin and alphadystroglycan. Development 122:1663-1672.

Chang D, Woo JS, Campanelli J, Scheller RH, Ignatius MJ (1997) Agrin inhibits neurite outgrowth but promotes attachment of embryonic motor and sensory neurons. Dev Biol 181:21-35.

Chen HJ, Rojas-Soto M, Oguni A, Kennedy MB (1998) A synaptic Ras-
GTPase activating protein (p135 SynGAP) inhibited by CaM kinase II. Neuron 20:895-904.

Cohen I, Rimer M, Lomo T, McMahan UJ (1997) Agrin-induced postsynaptic-like apparatus in skeletal muscle fibers in vivo. Mol Cell Neurosci 9:237-253.

Cohen MW, Godfrey EW (1992) Early appearance of and neuronal contribution to agrin-like molecules at embryonic frog nerve-muscle synapses formed in culture. J Neurosci 12:2982-2992.

Cohen MW, Jacobson C, Yurchenco PD, Morris GE, Carbonetto S (1997) Laminin-induced clustering of dystroglycan on embryonic muscle cells: comparison with agrin-induced clustering. J Cell Biol 136:1047-1058.

Cohen NA, Kaufmann WE, Worley PF, Rupp F (1997) Expression of agrin in the developing and adult rat brain. Neuroscience 76:581-596.

Cotman SL, Halfter W, Cole GJ (1999) Identification of extracellular matrix ligands for the heparan sulfate proteoglycan agrin. Exp Cell Res 249:54-64

Daggett DF, Cohen MW, Stone D, Nikolics K, Rauvala H, Peng HB (1996) The role of an agrin-growth factor interaction in ACh receptor clustering. Mol Cell Neurosci 8:272-285.

Davis GW, Goodman CS (1998) Genetic analysis of synaptic development and plasticity: homeostatic regulation of synaptic efficacy. Curr Opin Neurobiol 8:149-156.

DeChiara TM, Bowen DC, Valenzuela DM, Simmons MV, Poueymirou WT, Thomas S, Kinetz E, Compton DL, Rojas E, Park JS, Smith C, DiStefano PS, Glass DJ, Burden SJ, Yancopoulos GD (1996) The receptor tyrosine kinase $\mathrm{MuSK}$ is required for neuromuscular junction formation in vivo. Cell 85:501-512.

Dutton EK, Uhm CS, Samuelsson SJ, Schaffner AE, Fitzgerald SC, Daniels MP (1995) Acetylcholine receptor aggregation at nerve-muscle contacts in mammalian cultures: induction by ventral spinal cord neurons is specific to axons. J Neurosci 15:7401-7416.

Escher G, Bechade C, Levi S, Triller A (1996) Axonal targeting of agrin in cultured rat dorsal horn neurons. J Cell Sci 109:2959-2966.

Feldman DE, Knudsen EI (1998) Experience-dependent plasticity and the maturation of glutamatergic synapses. Neuron 20:1067-1071.

Ferns M, Hoch W, Campanelli JT, Rupp F, Hall ZW, Scheller RH (1992) RNA splicing regulates agrin-mediated acetylcholine receptor clustering activity on cultured myotubes. Neuron 8:1079-1086.

Ferns M, Deiner M, Hall Z (1996) Agrin-induced acetylcholine receptor clustering in mammalian muscle requires tyrosine phosphorylation. J Cell Biol 132:937-944.

Ferns MJ, Campanelli JT, Hoch W, Scheller RH, Hall Z (1993) The ability of agrin to cluster AChRs depends on alternative splicing and on cell surface proteoglycans. Neuron 11:491-502.

Ferreira A (1999) Abnormal synapse formation in agrin-depleted hippocampal neurons. J Cell Sci 112:4729-4738.

Fletcher TL, Cameron P, De Camilli P, Banker G (1991) The distribution of synapsin I and synaptophysin in hippocampal neurons developing in culture. J Neurosci 11:1617-1626.

Fletcher TL, De Camilli P, Banker G (1994) Synaptogenesis in hippocampal cultures: evidence indicating that axons and dendrites become competent to form synapses at different stages of neuronal development. J Neurosci 14:6695-6706.

Forti L, Bossi M, Bergamaschi A, Villa A, Malgaroli A (1997) Loosepatch recordings of single quanta at individual hippocampal synapses. Nature 388:874-878.

Gautam M, Noakes PG, Moscoso L, Rupp F, Scheller RH, Merlie JP, Sanes JR (1996) Defective neuromuscular synaptogenesis in agrin-deficient mutant mice. Cell 85:525-535.

Gramolini AO, Burton EA, Tinsley JM, Ferns MJ, Cartaud A, Cartaud J, Davies KE, Lunde JA, Jasmin BJ (1998) Muscle and neural isoforms of agrin increase utrophin expression in cultured myotubes via a transcriptional regulatory mechanism. J Biol Chem 273:736-743.

Halfter W, Schurer B, Yip J, Yip L, Tsen G, Lee JA, Cole GJ (1997) Distribution and substrate properties of agrin, a heparan sulfate proteoglycan of developing axonal pathways. J Comp Neurol 383:1-17.

Hemmati-Brivanlou A, Kelly OG, Melton DA (1994) Follistatin, an antagonist of activin, is expressed in the Spemann organizer and displays direct neuralizing activity. Cell 77:283-295.

Hilgenberg LG, Hoover CL, Smith MA (1999) Evidence of an agrin receptor in cortical neurons. J Neurosci 19:7384-7393.

Hoch W, Ferns M, Campanelli JT, Hall ZW, Scheller RH (1993) Developmental regulation of highly active alternatively spliced forms of agrin. Neuron 11:479-490.

Hoch W, Campanelli JT, Harrison S, Scheller RH (1994) Structural domains of agrin required for clustering of nicotinic acetylcholine receptors. EMBO J 13:2814-2821.

Hoffman KB (1998) The relationship between adhesion molecules and neuronal plasticity. Cell Mol Neurobiol 18:461-475.

Ji RR, Bose CM, Lesuisse C, Qiu D, Huang JC, Zhang Q, Rupp F (1998) Specific agrin isoforms induce cAMP response element binding protein phosphorylation in hippocampal neurons. J Neurosci 18:9695-9702.

Jones G, Meier T, Lichtsteiner M, Witzemann V, Sakmann B, Brenner HR (1997) Induction by agrin of ectopic and functional postsynaptic-like membrane in innervated muscle. Proc Natl Acad Sci USA 94:2654-2659.

Kim JH, Liao D, Lau LF, Huganir RL (1998) synGAP: a synaptic RasGAP that associates with the PSD-95/SAP90 protein family. Neuron 20:683-691. 
Klagsbrun M, Baird A (1991) A dual receptor system is required for basic fibroblast growth factor activity. Cell 67:229-231.

Li Z, Hilgenberg LG, O'Dowd DK, Smith MA (1999) Formation of functional synaptic connections between cultured cortical neurons from agrin-deficient mice. J Neurobiol 39:547-557.

Malgaroli A, Ting AE, Wendland B, Bergamaschi A, Villa A, Tsien RW, Scheller RH (1995) Presynaptic component of long-term potentiation visualized at individual hippocampal synapses. Science 268:1624-1628.

Martin PT, Sanes JR (1997) Integrins mediate adhesion to agrin and modulate agrin signaling. Development 124:3909-3917.

Matteoli M, Takei K, Perin MS, Sudhof TC, De Camilli P (1992) Exoendocytotic recycling of synaptic vesicles in developing processes of cultured hippocampal neurons. J Cell Biol 117:849-861.

McMahan UJ (1990) The agrin hypothesis. Cold Spring Harb Symp Quant Biol 55:407-418.

Meier T, Hauser DM, Chiquet M, Landmann L, Ruegg MA, Brenner HR (1997) Neural agrin induces ectopic postsynaptic specializations in innervated muscle fibers. J Neurosci 17:6534-6544.

Molnar E, McIlhinney RA, Baude A, Nusser Z, Somogyi P (1994) Membrane topology of the GluR1 glutamate receptor subunit: epitope mapping by site-directed antipeptide antibodies. J Neurochem 63:683-693.

Montanaro F, Gee SH, Jacobson C, Lindenbaum MH, Froehner SC, Carbonetto S (1998) Laminin and $\alpha$-dystroglycan mediate acetylcholine receptor aggregation via a MuSK-independent pathway. J Neurosci 18:1250-1260.

Nitkin RM, Smith MA, Magill C, Fallon JR, Yao YM, Wallace BG, McMahan UJ (1987) Identification of agrin, a synaptic organizing protein from Torpedo electric organ. J Cell Biol 105:2471-2478.

O'Brien RJ, Xu D, Petralia RS, Steward O, Huganir RL, Worley P (1999) Synaptic clustering of AMPA receptors by the extracellular immediateearly gene product Narp. Neuron 23:309-323.

O'Connor LT, Lauterborn JC, Gall CM, Smith MA (1994) Localization and alternative splicing of agrin mRNA in adult rat brain: transcripts encoding isoforms that aggregate acetylcholine receptors are not restricted to cholinergic regions. J Neurosci 14:1141-1152.

O'Connor LT, Lauterborn JC, Smith MA, Gall CM (1995) Expression of agrin mRNA is altered following seizures in adult rat brain. Brain Res Mol Brain Res 33:277-287.

Papa M, Bundman MC, Greenberger V, Segal M (1995) Morphological analysis of dendritic spine development in primary cultures of hippocampal neurons. J Neurosci 15:1-11.

Patthy L, Nikolics K (1993) Functions of agrin and agrin-related proteins. Trends Neurosci 16:76-81.

Rao A, Craig AM (1997) Activity regulates the synaptic localization of the NMDA receptor in hippocampal neurons. Neuron 19:801-812.

Rao A, Kim E, Sheng M, Craig AM (1998) Heterogeneity in the molecular composition of excitatory postsynaptic sites during development of hippocampal neurons in culture. J Neurosci 18:1217-1229.
Reist NE, Werle MJ, McMahan UJ (1992) Agrin released by motor neurons induces the aggregation of acetylcholine receptors at neuromuscular junctions. Neuron 8:865-868.

Ruegg MA, Tsim KW, Horton SE, Kroger S, Escher G, Gensch EM, McMahan UJ (1992) The agrin gene codes for a family of basal lamina proteins that differ in function and distribution. Neuron 8:691-699.

Rupp F, Payan DG, Magill-Solc C, Cowan DM, Scheller RH (1991) Structure and expression of a rat agrin. Neuron 6:811-823.

Rupp F, Ozcelik T, Linial M, Peterson K, Francke U, Scheller R (1992) Structure and chromosomal localization of the mammalian agrin gene. J Neurosci 12:3535-3544.

Sanes JR, Engvall E, Butkowski R, Hunter DD (1990) Molecular heterogeneity of basal laminae: isoforms of laminin and collagen IV at the neuromuscular junction and elsewhere. J Cell Biol 111:1685-1699.

Sanes JR, Apel ED, Burgess RW, Emerson RB, Feng G, Gautam M, Glass D, Grady RM, Krejci E, Lichtman JW, Lu JT, Massoulie J, Miner JH, Moscoso LM, Nguyen Q, Nichol M, Noakes PG, Patton BL, Son YJ, Yancopoulos GD, Zhou H (1998) Development of the neuromuscular junction: genetic analysis in mice. J Physiol (Paris) 92:167-172.

Serpinskaya AS, Feng G, Sanes JR, Craig AM (1999) Synapse formation by hippocampal neurons from agrin-deficient mice. Dev Biol 205:65-78.

Smith MA, Magill-Solc C, Rupp F, Yao YM, Schilling JW, Snow P, McMahan UJ (1992) Isolation and characterization of a cDNA that encodes an agrin like protein in the marine ray. Mol Cell Neurosci 3:406-415.

Stone DM, Nikolics K (1995) Tissue- and age-specific expression patterns of alternatively spliced agrin mRNA transcripts in embryonic rat suggest novel developmental roles. J Neurosci 15:6767-6778.

Sugiyama JE, Glass DJ, Yancopoulos GD, Hall ZW (1997) Laminininduced acetylcholine receptor clustering: an alternative pathway. J Cell Biol 139:181-191.

Tian M, Hagg T, Denisova N, Knusel B, Engvall E, Jucker M (1997) Laminin-alpha2 chain-like antigens in CNS dendritic spines. Brain Res 764:28-38.

Tsen G, Halfter W, Kroger S, Cole GJ (1995) Agrin is a heparan sulfate proteoglycan. J Biol Chem 270:3392-3399.

Tsim KW, Ruegg MA, Escher G, Kroger S, McMahan UJ (1992) cDNA that encodes active agrin. Neuron 8:677-689.

Tsui CC, Copeland NG, Gilbert DJ, Jenkins NA, Barnes C, Worley PF (1996) Narp, a novel member of the pentraxin family, promotes neurite outgrowth and is dynamically regulated by neuronal activity. J Neurosci 16:2463-2478

Wallace BG (1984) Staurosporine inhibits agrin-induced acetylcholine receptor phosphorylation and aggregation. J Cell Biol 125:661-668.

Whittaker VP (1984) The synaptosomes. In: Handbook of neurochemistry, Vol 7 (Lathia A, ed), pp 1-39. New York: Plenum. 